Editorial

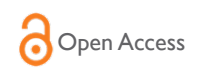

CrossMark

\title{
Rise of virtual drug design tools
}

\section{Editorial}

The invention of successful drug candidates or lead molecules always requires a brainstorming effort, laborious time and as well as a fortune. Hence asserting the drug-likeness properties of the lead molecule(s) at an early stage of the invention will efficiently propel the drug discovery. Nowadays there are a lot of in silico tools available (open access as well as copyrighted software) which can almost predict whether the proposed molecule(s) is going to be successful in further studies. There are various properties taken into account while screening through silico drug designing tools. For, e.g., solubility, topological polar surface area (TPSA), pKa, LogP, hydrogen bond donor/acceptor, molecular size, binding site, blood brain barrier penetration (for CNS drugs), rule of $5 .{ }^{1}$

Lipinski rule of five was the prime influential parameter while designing the drugs. More than a decade there was parallel research in the field of Fragment Based Drug Discovery (FBDD) ${ }^{2}$ was conducted. In the FBDD, two small chemical leads serve as building blocks for the outcome of a desired biological effect. This research showed a light on the rule of 3 (sometimes called as Astex's rule of 3$)^{3,4}$ and this rule serves as a basic platform for the FBDD. There are approximately 1080 references (since 1990's) showed up when the key word used as Fragment Based Drug Design during the SciFinder search. The search refined to the publication year between 2007 and 2017 ended up with the 986 references including 21 patents, clearly showed that there was a real progress happened in this area over the past fifteen years involving the FBDD concept. Recently, there are a number virtual screening/drug design tools available to develop the chemical leads/ drugs candidates. ${ }^{5,6}$

The synthetic chemists/medicinal chemists from academia can make use of the open access drug design tools to explore the therapeutic potency of the chemical leads apart from their prime focus of research area. It would efficiently drive the research and offer a prominence for the drug-leads as well as welcome the collaborators who are interested in the respective lead molecule(s). However, the intellectual property disclosure/non-confidential issues have a paramount importance in any area of the research. Hence the researchers have to aware about the policies before they post a structure of the molecule in any of the in silico screening tools to secure the intellectual property.

\section{Conclusion}

In conclusion, virtual drug design tools are inevitable in drug discovery but the correct choice of experimental screening conditions
Volume I Issue 2 - 2017

\author{
Michael Rajesh Stephen \\ Department of Chemistry and Biochemistry, University of \\ Wisconsin-Milwaukee, USA
}

Correspondence: Michael Rajesh Stephen, Department of Chemistry and Biochemistry, University of WisconsinMilwaukee, 3210 North Cramer Street, Milwaukee,Wisconsin 532 I I,USA, Tel + | 4|4-7| 2-4074, Email stephenm@uwm.edu

Received: July 27, 2017 | Published: July 28, 2017

is also equally important to achieve the same and desired result obtained from the virtual screening.

\section{Acknowledgements}

M.R.S sincerely thanks, National Institutes of Health (R01HL118561) for the financial support and University of WisconsinMilwaukee and the Milwaukee Institute for Drug Discovery for the research facilities.

\section{Conflict of interest}

The author declares that there is no conflict of interest regarding the publication of this article.

\section{References}

1. Singla D, Dhanda SK, Chauhan JS, et al. Open source software and web services for designing therapeutic molecules. Curr Top Med Chem. 2013;13(10):1172-1191.

2. Rees DC, Congreve M, Murray CW, et al. Fragment-based lead discovery. Nat Rev Drug Discov. 2004;3(8):660-672.

3. Congreve M, Carr R, Murray C, et al. A 'rule of three' for fragment-based lead discovery? Drug Discov Today. 2003;8(19):876-877.

4. Erlanson DA, McDowell RS, O’Brien T. Fragment-based drug discovery. J Med Chem. 2004;47(14):3463-3482.

5. Liu T, Naderi M, Alvin C, et al. Break Down in Order To Build Up: Decomposing Small Molecules for Fragment-Based Drug Design with eMolFrag. J Chem Inf Model. 2017;57(4):627-631.

6. McCarthy DJ, Campbell AJ, Kern G, et al. Fragment-based lead discovery and design. J Chem Inf Model. 2014;54(3):693-704. 